\title{
O ESTUDO DO COTIDIANO ESCOLAR NA EDUCAÇÃO PROFISSIONAL: REFLEXÃO SOBRE LUTAS DE CLASSES
}

\author{
Johny Henrique Magalhães Casado* \\ Katia Rodrigues Montalvão Paias** \\ Jonilce Costa Rodrigues***
}

RESUMO: O estudo do cotidiano tem ganhado cada vez mais a atenção da academia como fonte de se entender e compreender o ambiente escolar e suas idiossincrasias. Se faz natural então que pesquisadores, seja individualmente ou em grupos de pesquisa, se interessem em elaborar pesquisas sobre o assunto nos diferentes tipos de ambiente escolares que a sociedade apresenta. No presente artigo foram apresentados os principais conceitos relacionados ao estudo do cotidiano escolar e que estejam relacionados à educação profissional no Brasil. Como conclusão inicial observa-se que a educação profissional não possui muitos estudos relacionados na academia, considerando as recentes mudanças na Base Nacional Comum Curricular que alterou significativamente o ensino médio e inseriu de vez a educação profissional na vida escolar de milhões de alunos, e percebe-se que compreender o cotidiano escolar dessa modalidade é condição indispensável para contribuir com o debate e busca pela qualidade no ensino.

PALAVRAS-CHAVE: Educação profissional; Luta de classes; Sistema S.

\section{DAILY LIFE IN SCHOOL WITHIN PROFESSIONAL EDUCATION: REFLECTIONS ON CLASS STRUGGLE}

ABSTRACT: Studies on daily life in school has been in the academy's limelight as a source of understanding school environment and its idiosyncrasies. Individual and group researchers are naturally interested with regard to research work in different types of school environment presented by society. Current paper presents the main ideas on the study of daily life in school related to professional education in Brazil. Professional education lacks studies by the academy when the recent modification

\footnotetext{
* Mestrando do Programa em Ciências Contábeis da Universidade Estadual de Maringá (UEM), Brasil. E-mail: johny.hmc@gmail.com

** Mestranda do Programa em Educação da Universidade do Oeste Paulista (UNOESTE), Brasil.

**** Mestranda em Educação para a Ciência e a Matemática na Universidade Estadual de Maringá (UEM), Brasil.
} 
in the National Common Basic Curriculum is taken into account. In fact, the latter altered significantly high school and inserted professional education within the school for millions of students. One may perceive that understanding daily life in school is an indispensable condition towards debate and teaching quality.

KEY WORDS: Professional education; Class struggle; System S.

\section{INTRODUÇÃO}

A função do pesquisador pode ser interpretada de diversas formas, dentre elas que é de responsabilidade dele destacar algo que está ao mesmo tempo oculto e flagrante no momento retratado, para tanto a necessidade de uma sociologia mais atenta às questões do cotidiano tem ganhado cada vez mais espaço nas discussões acadêmicas (MAFESOLI, 2008). Considerar a contribuição de marxistas na compressão da sociedade é parte importante para se compreender o papel do capitalismo no campo da educação. Para Saviani (1991, p. 14) "o Capitalismo continua sendo ainda a forma predominante. Portanto, Marx continua sendo não apenas uma referência válida, mas a principal referência para compreendermos a situação atual”.

O registro da história até os Annales se dava apenas para gravar os grandes eventos e grandes personalidades, os "pequenos" fatos eram, então, subjugados e não mereciam ser retratados para a posteridade. Imbuídos do princípio de renovação e da criação de uma nova forma de se registrar os fatos históricos, os historiadores passaram a registrar a história de forma plural, os sujeitos passaram a ser relevantes e dignos de registro independente de seu envolvimento em algum fato histórico, o sujeito passou a ser protagonista de sua própria história (MAFESOLI, 2008; BONFIM, 2013). Ao basear estudos sobre educação se utilizando da pedagogia históricocritica é, segundo Saviani (2003, p.88) garantir ao "materialismo histórico, ou seja, a compreensão da história a partir do desenvolvimento material, da determinação das condições materiais da existência humana”.

Considerando o papel do pesquisador em registrar o cotidiano, neste artigo, em especial o cotidiano escolar, e conjecturando com a necessidade do registro 
do indivíduo como centro dos acontecimentos, este artigo vislumbra dedicar-se ao estudo do cotidiano na educação profissional no Brasil, fenômeno que necessita ser estudado cada vez mais, já que desde a década de 50 a educação profissional foi terceirizada ao capital por meio de entidades intituladas como "Sistema S". No dizer de Saviani (1999, p. 41-42) "é necessário avançar no sentido de captar a natureza específica da educação, o que nos levará à compreensão das complexas mediações pelas quais se dá sua inserção contraditória na sociedade capitalista".

Saviani proporcionou com seu livro Escola e Democracia o marco teórico necessário para aprofundamento da reflexão sobre a educação profissional, o autor trouxe o conceito de "pedagogia tecnicista dir-se-ia que é o processo que define o que professores e alunos devem fazer, e assim também quando e como o farão" (SAVIANI, 1999, p.25).

Visando atingir o objetivo de retratar o cotidiano escolar sob a chave teórica da luta de classe a presente pesquisa está dividida em três seções, sendo a primeira seção a responsável por conceituar o estudo do cotidiano escolar e sua evolução histórica. A segunda parte abordará brevemente a educação profissional e como essa está organizada no Brasil, a terceira e última parte apresentará um breve levantamento sobre os principais trabalhos publicado sobre cotidiano escolar na educação profissional. Por fim, serão apresentadas as principais conclusões obtidas com essa pesquisa.

\section{RECURSOS METODOLÓGICOS}

Segundo Marconi e Lakatos (2006), a pesquisa permite o conhecimento da realidade ou o descobrimento de verdades parciais por meio de um processo formal e uma metodologia de pensamento reflexivo, sendo assim a pesquisa possibilita ampliar os conhecimentos sejam eles científicos, acadêmicos ou profissionais.

Em relação aos recursos metodológicos utilizados destaca-se que essa pesquisa adquire um caráter qualitativo. Para Richardson (1999, p. 90) esse tipo de pesquisa "[...] pode ser caracterizada como tentativa de uma compreensão detalhada dos significados e características situacionais apresentadas pelos entrevistados, em 
lugar da produção de medidas quantitativas de características ou comportamentos".

O método qualitativo, segundo Minayo (2011, p. 21), é definido como "a pesquisa qualitativa [que] responde a questões muito particulares. Ela se ocupa, nas Ciências Sociais, como um nível de realidade que não pode ou não deveria ser quantificado". A pesquisadora acrescenta que esta pesquisa "[...] trabalha com o universo dos significados, dos motivos, das aspirações, das crenças, dos valores e das atitudes".

Em se tratando da coleta das informações referentes à publicação dos artigos relacionados à temática da pesquisa, destaque-se que as informações foram obtidas por meio de dados secundários obtidos junto a plataforma de busca EBSCO. Esse portal é um dos maiores fornecedores de conteúdo científicos para a academia, sendo que a busca de artigos funciona no mesmo formato em que buscadores da internet.

\section{O COTIDIANO ESCOLAR E A DEMOCRACIA}

A sociedade é o resultado de uma sequência de pequenos gestos que acontecem no cotidiano das pessoas. A distinção entre a vida pública e privada ocorreu no século XIX com o fim da sociedade de corte, em que cada coisa era tratada em seu devido espaço fosse ele público ou privado. O espaço privado era visto como o lugar das "permanências culturais", ou seja, um espaço que conserva, que é ritualístico e que tem a tradição como norteadora de suas ações. O espaço público é o espaço dos grandes poderes, de produção e da transformação. No século XVIII a história do cotidiano era vista como um saber marginal, mais como um divertimento do que como história de fato (DEL PRIORE, et al, 1997).

Para Saviani (1991, p. 19) compreender a educação e o trabalho se faz necessário para compreender a própria sociedade:

Sabe-se que a educação é um fenômeno próprio dos seres humanos. Assim sendo, a compreensão da natureza da educação passa pela compreensão da natureza humana. Ora, o que diferencia os homens dos demais fenômenos, o que o diferencia dos demais seres vivos, o que o diferencia dos outros animais? A resposta a essas questões também já é conhecida. 
Com efeito, sabe-se que, diferentemente dos outros animais, que se adaptam à realidade natural tendo a sua existência garantida naturalmente, o homem necessita produzir continuamente sua própria existência. Para tanto, em lugar de se adaptar à natureza, ele tem que adaptar a natureza a si, isto é, transformá-la. E isto é feito pelo trabalho. E o trabalho se instaura a partir do momento em que seu agente antecipa mentalmente a finalidade da ação. Consequentemente, o trabalho não é qualquer tipo de atividade, mas uma ação adequada a finalidades. É, pois, uma ação intencional.

A compreensão do cotidiano pode ser entendida pelos escritos de Maffesoli (2001, p 18) que considera "como o lugar a partir do qual se fundamos vínculos sociais. Assim, tratar-se ia de considerar a vida "sem qualidade", que escapa às diversas instâncias dos poderes (econômica, política, simbólica), e que assegura, na longa duração, a permanência da espécie”.

Pesquisar sobre o cotidiano não é simplesmente relatar o dia a dia, mas observar o cotidiano nas menores rotinas possíveis, seria por meio dessas pequenas rotinas que ocorrem os grandes rompimentos que fazem surgir mudanças maiores. O pesquisador que se aventura no estudo de cotidiano lida com uma quantidade de fontes de pesquisa muito grande, sendo assim, seu maior trabalho é a construção de coesão (criar uma conexão/buscar os nexos) entre essa quantidade de fontes (MATOS, 2002, p. 30-1 apud BONFIM, 2013, p 115).

Ocorridos inicialmente nos Estados Unidos, os estudos sobre o cotidiano no ambiente escolar são comparados muitas vezes a uma "caixa preta" pelos pesquisadores, essa metáfora visa explicitar o desinteresse que até então existia com os processos e acontecimentos que ocorriam dentro do ambiente escolar; sempre se buscou mais pelos "resultados" que a escola poderia gerar e menos por como eles foram alcançados ou não (ALVES, 2003, p. 64).

Compreender por meio de um estudo aprofundado do cotidiano escolar "oferece uma perspectiva privilegiada de análise, pronta a subverte concepções universalistas, cristalizadas pela historiografia tradicional, evidenciando uma multiplicidade de sujeitos históricos, bem como de temas antes desprezados" (BONFIM, 2013, p 108). 
Quando o pesquisador lança seu olhar sobre um ambiente visando compreender os acontecimentos cotidianos é importante que ele considere que nem sempre o que é observado é real. Ações, atitudes, interações tudo pode ser representado, o "eu" e suas relações sociais nem sempre pode ser observado facilmente pelo pesquisador. Os indivíduos sempre estão representando e fazendo uso de máscaras que podem ser trocadas dependendo de cada situação (GOFFMAN, 1985). O estudo do cotidiano na escola se torna então de suma importância para qualquer pesquisador que pretenda produzir conhecimentos relevantes.

Em sua obra "Educação e Democracia", Saviani (1999) demonstra que a educação tecnicista proposta com a educação profissional visa, dentre outras coisas, capacitá-lo apenas para a produtividade em funções, impedindo assim a formação de um sujeito capaz de alterar sua realidade e da sociedade. Com a educação profissional como pensada até então, a tônica tecnicista visará uma educação concebida "como um subsistema, cujo funcionamento eficiente é essencial ao equilíbrio do sistema social de que faz parte" (SAVIANI, 1999, p. 25). O aprender a fazer substitui o aprender a aprender, forma-se então, um contingente incapaz de questionar a sociedade onde está inserida, algo cômodo para as classes dominantes que não terão sua posição ameaçada.

A pedagogia tecnicista impera até nos dias atuais nas diferentes escolas profissionais do Brasil, somente quando houver reflexão necessária sobre o tema é que se poderá evoluir para uma pedagogia que realmente atenda às necessidades dos alunos. A falta de autonomia ao aluno e ao professor, faz com que esse tipo de escola acaba por perpetuar uma sociedade injusta e cada vez menos igualitária. $\mathrm{O}$ uso da pedagogia tecnicista acabou por:

[...] contribuir para aumentar o caos no campo educativo gerando tal nível de descontinuidade, de heterogeneidade e de fragmentação, que praticamente inviabiliza o trabalho pedagógico. Com isto, O problema da marginalidade só tendeu a se agravar: o conteúdo do ensino tornou-se ainda mais rarefeito e a relativa ampliação das vagas se tornou irrelevante em face dos altos índices de evasão e repetência (SAVIANI, 1999, p. 26). 
A escola deve se inserir no processo para criar uma sociedade mais ampla e voltada para as forças emergentes populares existentes na sociedade, infelizmente, o que se vê é a burguesia atuando de forma hegemônica com mecanismos que lhe garanta a manutenção de seus privilégios. Um dos enfoques diante da educação profissional, é que as maiores redes de ensino profissional do país, estão nas mãos de entidades empresariais administradas por sindicatos patronais; essas empresas acabam por reproduzir a dinâmica atual da sociedade, em que a burguesia acaba por definir o que e como o filho do proletariado irá estudar.

\section{EDUCAÇÃO PROFISSIONAL: CONTEXTUALIZAÇÃO}

A educação no Brasil tem uma diversidade de estudos acadêmicos e resgates históricos que de uma forma geral produz inúmeros artigos, publicações, estudos acadêmicos, livros e outros recursos de pesquisa, isso faz com que haja muitas pesquisas em diversas áreas da educação. Essa mesma diversidade e variedade de pesquisas não é encontrada quando o campo de estudo se afunila para a educação profissional, é notória a escassez de pesquisadores e principalmente materiais que tragam de fato um retrato nítido e fiel dos desdobramentos desse setor da educação no decorrer dos séculos em nosso país. O estudo da educação profissional, seja ela integrado ao nível médio ou sequencial, permitirá recuperar o papel da "escola de nível médio será, então, o de recuperar essa relação entre o conhecimento e a prática do trabalho" (SAVIANI, 2007, p. 14).

Contudo, não é possível afirmar que a educação profissional não tenha chamado a atenção dos pesquisadores pela sua pouca relevância acadêmica, isso ocorreu a princípio por ela sempre ser vinculada às classes trabalhadoras e ter conotação popular. Compreender a educação profissional é condição sine qua non para compreender o atual estágio de evolução da sociedade. Para Saviani (2003, p. 138) "o ensino profissional é destinado àqueles que devem executar, ao passo que o ensino científico-intelectual é destinado àqueles que devem conceber e controlar o processo". Reforça ainda essa ideia, o fato que a dicotomia entre "o trabalho Intelectual e manual, na qual o primeiro é destinado aos filhos da classe 
burguesa e o segundo aos filhos da classe trabalhadora" (PORTO, 2015, p. 459) não contribuindo desse modo para a emancipação humana.

O espaço vazio de estudos na área se explica, pelo menos em parte, pelo fato de que os historiadores da educação brasileira se preocuparem com o ensino destinado às elites políticas e ao trabalho intelectual, relegando ao trabalho manual posição secundária (CUNHA, 2000). Para Saviani (2012, p. 55), "o dominado não se liberta se ele não vier a dominar aquilo que os dominantes dominam. Então, dominar o que os dominantes dominam é condição de libertação". Destarte, compreender a educação profissional como ponto de mudança da sociedade é contribuir para atenuar as diferenças entre as classes.

A educação profissional está intimamente ligada à necessidade de formação de mão-de-obra qualificada para o mercado de trabalho, sendo assim, ela afeta as relações de trabalho e se modifica com o progresso tecnológico que a sociedade experimenta ao longo do tempo. Nela, o "conhecimento deve estar a serviço de um compromisso político de fortalecer a classe trabalhadora nas suas ações na luta de classes, a fim de superar o modo de produção vigente" (PORTO, 2015, p. 471).

Nesses termos, a exigência por qualificação do mercado de trabalho em nossa trajetória, nos conduz a observarmos em qual momento histórico das relações de trabalho influencia e estimula essa demanda por qualificação. Percebemos que a década de 1970 se apresenta como um marco de profundas transformações nas relações de trabalho. Essas transformações colocam em questão o papel da escola como espaço de libertação e transformação, porém, há claros movimentos da classe dominante em tentar "impedir o desenvolvimento da ideologia do proletariado e a luta revolucionária” (SAVIANI, 2008, p. 22-23).

A partir da década de 1970, mudanças tecnológicas e organizacionais atingiram o mundo do trabalho, contribuindo para a emergência de novas características tendenciais no sistema de produção capitalista (GERALDINO, 2015). As transformações políticas, sociais e econômicas ocorridas no Brasil, em corroboradas com a criação do Sistema S (SENAC, SESC, SENAI, SESI, SENAR) no período pósguerra, culminou com inúmeras mudanças no setor da educação profissional nas décadas de 80, 90 e anos 2000.

Em 2002 com a mudança de governo no Brasil, o presidente eleito Lula 
tratou de intensificar as políticas de qualificação profissional, alterando o até então Plano Nacional de Formação do Trabalhador (PLANFOR) para o Plano Nacional de Qualificação (PNQ). Esse plano incluiu os ministérios no desenvolvimento de políticas públicas de qualificação para o trabalho, articulando o trabalho (via Ministério do Trabalho - MTE) e a educação (via Ministério da Educação - MEC) ao desenvolvimento social (via Ministério do Desenvolvimento Social e Combate à Fome - MDS). Tratava-se de uma política com forte direcionamento aos grupos que apresentam vulnerabilidades sociais, com maiores percentuais de desemprego e pobreza, cabendo à educação profissional a função de qualificar e requalificar o cidadão trabalhador para o mercado de trabalho (GERALDINO, 2015).

A evolução da educação profissional se deu nos anos seguintes a chegada de Luis Inácio Lula da Sila à presidência (2003-2011), com o governo de continuidade da presidenta Dilma Rousseff (2011-2016) as políticas públicas voltadas à educação profissional se consolidaram em torno de um novo programa governamental. Ao expandir a educação profissional via organizações do "Sistema S" o governo visava apassivar a luta de classe, os cursos oferecidos via PRONATEC tinha a intenção de tornar a educação oferecida uma "atividade mediadora no seio da prática social global" (SAVIANI, 2008, p. 59). O "Sistema S" é o:

Termo que define o conjunto de organizações das entidades corporativas voltadas para o treinamento profissional, assistência social, consultoria, pesquisa e assistência técnica, que além de terem seu nome iniciado com a letra $S$, têm raízes comuns e características organizacionais similares. Fazem parte do sistema S: Serviço Nacional de Aprendizagem Industrial (Senai); Serviço Social do Comércio (Sesc); Serviço Social da Indústria (Sesi); e Serviço Nacional de Aprendizagem do Comércio (Senac). Existem ainda os seguintes: Serviço Nacional de Aprendizagem Rural (Senar); Serviço Nacional de Aprendizagem do Cooperativismo (Sescoop); e Serviço Social de Transporte (Sest) (SENADO FEDERAL, 2019, online).

No dia 26 de outubro do ano de 2011, o governo sanciona a lei de $\mathrm{n}^{\circ} 12.513$, que oficializa a implementação do Programa Nacional de Acesso ao Ensino Técnico e Emprego (PRONATEC), tendo como objetivo geral expandir a oferta de cursos de 
educação profissional e tecnológica. O Pronatec se destaca por estabelecer diversas ações articuladas intersetoriais, tendo como foco a educação profissional e tecnológica na busca pelo desenvolvimento do país, por meio da inclusão e promoção social, inovação tecnológica e aumento da produtividade e competitividade da economia.

O Pronatec possuía alguns objetivos que foram a importância para a consolidação e a expansão da educação profissional no Brasil, dentre eles os principais objetivos são:

expandir, interiorizar e democratizar a oferta de cursos de educação profissional técnica de nível médio presencial e à distância e de cursos e programas de formação inicial e continuada ou qualificação profissional; fomentar e apoiar a expansão da rede física de atendimento da educação profissional e tecnológica; contribuir para a melhoria da qualidade do ensino médio público, por meio da articulação com a educação profissional; ampliar as oportunidades educacionais dos trabalhadores, por meio do incremento da formação e qualificação profissional; estimular a difusão de recursos pedagógicos para apoiar a oferta de cursos de educação profissional e tecnológica, e estimular a articulação entre a política de educação profissional e tecnológica e as políticas de geração de trabalho, emprego e renda.(BRASIL, 2011).

É importante ressaltar que a oferta desses cursos dependia das condições técnicas e estruturais das instituições ofertantes (SÁ, 2016).

Ao se considerar a educação profissional como objeto de estudo não se deve esquecer sobre a evolução que ela apresentou nos últimos dez anos no Brasil, devese considerar também a sua efetividade sob o ponto de vista de atendimento das premissas de formação de mão de obra qualificada, geração de renda e aumento da empregabilidade dos alunos egressos. A importância de se aumentar a quantidade de estudos relacionados à formulação de políticas públicas para a educação profissional já seria motivo mais do que suficiente para se desenvolver a presente pesquisa. 


\section{PESQUISA SOBRE COTIDIANO ESCOLAR NA EDUCAÇÃO PROFISSIONAL}

Com o intuito de atender o objetivo inicial desse artigo, de realizar um cruzamento entre as produções acadêmicas a respeito de cotidiano escolar na educação profissional, realizou-se uma pesquisa através da plataforma EBSCO, que é considerada a maior fornecedora mundial de conteúdos científicos disponibilizando mais de meio milhão de artigos nas diferentes áreas do conhecimento.

Dentre os critérios de pesquisa, faz-se necessário esclarecer que a pesquisa realizada teve como recorte temporal o período compreendido entre os anos 2000 a 2017. Outro funil utilizado como parâmetro para a pesquisa foi condicionar todos os resultados a área de educação, assim, espera-se obter uma maior assertividade com a pesquisa realizada.

Considerando os parâmetros acima expostos e o recorte temporal, constatouse a existência de 223 artigos a respeito do tema pesquisado, desses seguem os cinco mais citados e de maior relevância segundo a EBSCO serão apresentados a seguir.

O primeiro artigo intitulado "Buscando e reconhecendo direitos: a produção de conhecimento sobre educação escolar quilombola" foi a produção acadêmica originada da pesquisa "A Educação Profissional e a permanência de estudantes quilombolas no IFRN: uma análise para além da Lei $n^{\circ}$ 12.711/2012”. O principal objetivo desse artigo foi de realizar um levantamento da produção acadêmica acerca da educação escolar voltada para os jovens quilombolas no Brasil, ele foi publicado no ano de 2017.

Intitulado de "Educação social: quando o passado é desafio presente na formação docente", o segundo artigo teve como objetivo refletir acerca da relação entre a psicanálise e a educação enquanto campo de saber produzido por meio das práxis educativas. O saber subjetivo implicado com o ato educativo e os laços sociais produzidos no cotidiano escolar são dimensões estruturantes à prática e à formação do profissional da educação, no que tange à relação do sujeito com o desejo e o saber. Em contraste à tradicional visão da psicologia 'aplicada à Educação', certa leitura da psicanálise tem contribuído para pensarmos os laços sociais produzidos em nome da educação, caminho aberto para refletirmos a implicação do sujeito na formação e profissão docente. O artigo em questão foi publicado também no ano de 2017. 
O terceiro artigo destacado pela sua relevância e número de citações também foi publicado no ano de 2017, cujo o título é "Assistência estudantil brasileira e a experiência da Uerj: entre a inovação e o atraso na atenção ao estudante" e teve como objetivo norteador apresentar a política de assistência estudantil brasileira em sua trajetória histórica e em conexão com o trabalho dos assistentes sociais. Nesse artigo analisou-se a experiência de atenção ao estudante construída na Uerj, refletindo acerca das potencialidades não exploradas contidas nesta instituição. Por fim, destacou-se a importância da constituição de uma efetiva assistência estudantil na Uerj.

O penúltimo artigo, também publicado em 2017, destacado pela plataforma EBSCO, tem como título "A formação do trabalhador e da trabalhadora numa perspectiva Freiriana", dentre os objetivos desse artigo o destaque para a busca de categorias fundantes para uma reflexão crítica da formação profissional do trabalhador e da trabalhadora de modo a delinear o que seja um caminho libertador e emancipador para a formação destes na atualidade. A partir da categoria do ser sujeito, demonstra-se como o trabalhador e a trabalhadora constituem-se atores de sua história e criadores de seu mundo; nas categorias do tema-gerador, do diálogo, da educação como prática da liberdade, verifica-se que o sentido da expressão formação dos trabalhadores só pode ser compreendido em sua dimensão libertadora; e, nas categorias da participação, da militância e da educação como ato político, comprovase que uma formação libertadora resulta na atuação consciente do trabalhador e trabalhadora sobre o mundo vivido para transformá-lo.

O quinto e último artigo aqui apresentado, tem como título a "Gestão do conhecimento nas relações da sociedade da informação pela web" e trata das diferenças culturais existentes entre as gerações de professores e alunos da educação profissional; a web tem a capacidade de proporcionar desses profissionais a fim de torná-los agentes transformadores das novas gerações, aproximando-os pelo conhecimento e os auxiliando na compreensão da realidade além dos links da internet e equilibrando, ao mesmo tempo, o contexto da aula.

Dentre os artigos apontados como mais recentes e relevantes pela plataforma, pode-se perceber a enorme diversidade de temas que pesquisadores e grupos de pesquisa podem encontrar ao optarem por pesquisar sobre o cotidiano 
escolar na educação profissional. Uma pesquisa mais aprofundada poderia ser realizada visando categorizar os temas e apresentar quais delineamentos são mais relevantes ao se estudar os temas.

\section{CONCLUSÕES}

O estudo do cotidiano escolar tem ganhado cada vez mais importância nas pesquisas acadêmicas acerca da educação, trabalhos importantes e relevantes são produzidos todos os anos nos Estados Unidos e na Europa sobre o tema. No Brasil diversos pesquisadores e grupos de pesquisa têm se debruçado sobre o tema e produzido ótimas pesquisas que têm balizados os demais pesquisadores acerca dessa temática.

A educação profissional apesar do expressivo aumento do número de alunos ainda não ganhou relevância como tema de pesquisas acadêmicas como a educação superior por exemplo. Tornar esse tema fonte de pesquisa será uma tarefa importante para todos os pesquisadores, ainda mais no atual momento em que a educação profissional se integrará com o ensino médio após a adoção da base nacional curricular comum.

Compreender os processos de permanências e mudanças, no cotidiano de uma instituição escolar que oferece a educação profissional ganhará cada vez mais relevância para pesquisas e pesquisadores. Observou-se com a pesquisa na plataforma EBSCO que ambas as temáticas já têm encontrado uma infinidade de possibilidades para serem trabalhadas em conjunto.

Com o estudo baseado na criticidade proposta por Saviani (2012), uma análise mais aprofundada da educação profissional precisa ser realizada por parte da academia, a luta de classes também acontece nesse campo, deixar que organizações como o "Sistema S" acabe por tomar as rédeas da educação profissional no Brasil é, no mínimo, temerário. O binômio mecanicista-produtivista não pode continuar a simbolizar a educação profissional, para isso, professores, pesquisadores, alunos e trabalhadores, necessitam compreender qual modelo de educação profissional é desejado, essa mudança; somente será possível com o aprofundamento dos estudos existentes e o surgimento de novos estudos. 
A vasta obra apresentada por Saviani versa sobre inúmeros pontos possíveis para repensar o papel da escola na construção da sociedade, utilizando-se desse prisma para analisar a educação profissional. Fica claro, que são necessárias urgentes mudanças. O trabalhador necessita ganhar voz e vez na sociedade, a escola necessita ser inclusiva e capaz de criar um ambiente que propicie ao trabalhador reflexão sobre seu papel social, a burguesia não pode ser constantemente empoderada e detentora das rédeas, em suma, a hegemonia vigente necessita ser questionada. A educação profissional deve existir, porém, não pode ser instrumento de massificação do aprender a fazer, ela deve ser o meio pelo qual trabalhadores se percebam como agentes de mudança de sua história e da própria sociedade.

A reflexão proposta por Saviani (2012) continua viva na sociedade atual, não se deve esperar que programas como PRONATEC proporcionem o apassivamento da luta de classes, esse tipo de programa não pode ser fim, ele tem de ser meio de transformação do status quo da sociedade, para isso, o trabalhador necessita ser parte do processo. Continuar a terceirizar a educação profissional para entidades profissionais não é o caminho para uma sociedade mais justa e igualitária, sendo assim, o trabalhador necessita ganhar vez e voz na formulação de políticas públicas como essas.

Como sugestão de estudos futuros nota-se que a mesma pesquisa poderia repetir-se utilizando de outras bases de artigos acadêmicos, maximizando ainda mais o conhecimento a respeito desse tema.

\section{REFERÊNCIAS}

ALVES, N. Cultura e cotidiano escolar. Revista Brasileira de Educação, Rio de Janeiro, n.23, Ag. 2003. Disponível em: http://www.ia.u frrj.br/ppgea/conteudo/ conteudo-2009-2/Educacao-MII/2SF/Cultura_e_Cotiadia no.pdf. Acesso em: 05 jan. de 2018.

BONFIM, P. R. O cotidiano na nouvelle histoire: um campo de investigação fértil de outras histórias. Revista Científica E-Locução, v. 1, p. 106-117, 2013.

\section{CUNHA, L. A. O ensino de ofícios artesanais e manufatureiros no Brasil} escravocrata. São Paulo: Ed. UNESP, 2000a. 
CUNHA, L. A. O ensino de ofícios nos primórdios da industrialização. São Paulo: Ed. UNESP, 2000b.

DEL PRIORE, M. História do cotidiano e da vida privada. In: CARDOSO, C. F. S. et al. Domínios da História: Ensaios de teoria e metodologia. Rio de Janeiro: Campus, 1997. p. 376-398.

GOFFMAN, E. A representação do eu na vida cotidiana. Petrópolis: Vozes, 1985.

GERALDINO, G. C. L. Políticas públicas de qualificação para o trabalho:

o Pronatec em discussão. 2015. 179f. Dissertação (Mestrado em Educação) Universidade Estadual de Maringá, Maringá, 2015.

MARCONI, M. A.; LAKATOS, E. M. Fundamentos de metodologia científica. 6. ed. São Paulo: Atlas, 2006.

MAFFESOLI, M. A conquista do presente. Natal: Argos, 2001.

MAFFESOLI, M. O conhecimento comum: compêndio de sociologia compreensiva. Trad. Aluízio Ramos Trinta. São Paulo: Brasiliense, 1988.

MINAYO, M.C. de S. O desafio do conhecimento: pesquisa qualitativa em saúde. São Paulo: Hucitec-Abrasco, 2010.

PORTO, C. C. B. A. A educação da classe trabalhadora: de Marx a Saviani. Revista Contemporânea de Educação, v. 10, n. 20, jul./dez. 2015.

RICHARDSON, R. J. Pesquisa social: métodos e técnicas. São Paulo: Atlas, 1999.

SAVIANI, D. Educação e questões da atualidade. São Paulo: Livros do Tatu, Cortez, 1991.

SAVIANI, D. Pedagogia histórico-crítica: primeiras aproximações. 8. ed. Campinas, São Paulo: Autores Associados, 2003. (Coleção Educação Contemporânea). 
SAVIANI, D. Escola e Democracia. 32. ed. Campinas-SP: Autores Associados, 1999. (Coleção polêmicas do nosso tempo, v. 5).

SAVIANI, D. Educação e questões da atualidade. São Paulo: Livros do Tatu, Cortez, 1991.

SAVIANI, D. O plano de desenvolvimento da educação: análise do projeto do MEC. Educação e Sociedade, Campinas, v. 28, n. 100 Especial, out. 2007.

SAVIANI, D. O Choque Teórico da politecnia. Trabalho, Educação e Saúde, Rio de Janeiro, v. 1, n. 1, 2003.

SAVIANI, D. História, trabalho e educação: comentários sobre as controvérsias internas ao campo marxista. In: SAVIANI, D; DUARTE, N. (org.). Pedagogia histórico-crítica e luta de classes na educação escolar. Campinas: Autores Associados, 2012. p. 167-182.

SAVIANI, D. Escola e democracia. Campinas: Autores Associados, 2008.

Recebido em:13/01/2019

Aceito em: 18/07/2019 